Journal of Tropical Ecology

http://journals.cambridge.org/TRO

Additional services for Journal of Tropical Ecology:

Email alerts: $\underline{\text { Click here }}$

Subscriptions: $\underline{\text { Click here }}$

Commercial reprints: $\underline{\text { Click here }}$

Terms of use : $\underline{\text { Click here }}$

\title{
Importance of interaction frequency in analysis of ant-plant networks in tropical environments
}

Wesley Dáttilo, Ingrid Sánchez-Galván, Denise Lange, Kleber Del-Claro and Víctor Rico-Gray

Journal of Tropical Ecology / Volume 30 / Issue 02 / March 2014, pp 165 - 168

DOI: 10.1017/S0266467413000813, Published online: 13 December 2013

Link to this article: http://journals.cambridge.org/abstract_S0266467413000813

How to cite this article:

Wesley Dáttilo, Ingrid Sánchez-Galván, Denise Lange, Kleber Del-Claro and Víctor Rico-Gray (2014). Importance of interaction frequency in analysis of ant-plant networks in tropical environments . Journal of Tropical Ecology, 30, pp 165-168 doi:10.1017/S0266467413000813

Request Permissions : $\underline{\text { Click here }}$ 


\title{
SHORT COMMUNICATION
}

\section{Importance of interaction frequency in analysis of ant-plant networks in tropical environments}

\author{
Wesley Dáttilo*,1, Ingrid Sánchez-Galván†, Denise Langeł, Kleber Del-Claroł and Víctor Rico-Gray* \\ * Instituto de Neuroetología, Universidad Veracruzana, Xalapa, Veracruz, 91190, Mexico \\ † CIBIO, Universidad de Alicante, San Vicente del Raspeig (Alicante), 03080, Spain \\ ¥ Laboratório de Ecologia Comportamental e Interações, Instituto de Biologia, Universidade Federal de Uberlândia, Uberlândia, Minas Gerais, 38400-058, Brazil \\ (Received 15 August 2013; revised 13 November 2013; accepted 14 November 2013; first published online 13 December 2013)
}

\begin{abstract}
Several studies have shown that qualitative (binary) ant-plant networks are highly nested in tropical environments, in which specialist species (with fewer interactions) are connected with generalists (with the most interactions) in cohesive subgroups. Interactions occur in both qualitative and quantitative networks, however, how their frequency may structure the nestedness in ecological networks involving these organisms is, we believe, unknown. Based on this perspective, we used nestedness analysis to address the effect of interaction frequency on antplant networks ( $\mathrm{n}=14$ networks). Unlike binary networks, quantitative networks are often significantly non-nested. In addition, species with a higher interaction frequency have a higher number of links, indicating that these species are possibly more abundant and/or competitive. Moreover, different biological parameters can change the nature of ant-plant interactions, as a plant can be a good resource for one ant and a 'bad' resource for another. Thus, this suggests a new perspective for the study of interaction networks in the tropics, since species with lower interaction frequency are not necessarily subsets of species with higher frequency, and consequently generate the non-nested pattern in quantitative networks.
\end{abstract}

Key Words: Ant-plant interactions, ecological networks, nestedness, qualitative networks, quantitative networks

Recent studies have focused on ecological networks and found a highly nested pattern for different systems and habitats (Bascompte et al. 2003). In a nested network, specialist species (with fewer interactions) are connected with generalists (with the most interactions) in cohesive subgroups (Bascompte et al. 2003). Metrics based on binary (or qualitative) matrices have been developed to describe such nested patterns (Ulrich et al. 2009). In these matrices, all interactions are ecologically equivalent, and individual differences of interactions are not taken into account (Almeida-Neto \& Ulrich 2011). However, in the natural environment, free-living species interact quantitatively generating a complex system of interactions, which allows the study of species preferences (Blüthgen 2010), and some authors have criticized nestedness analysis in binary matrices (Almeida-Neto \& Ulrich 2011).

\footnotetext{
${ }^{1}$ Corresponding author. Email: wdattilo@hotmail.com
}

Ant-plant associations are a useful system to study questions of the importance of interaction frequency in interaction networks, because ant-plant interactions are relatively easy to quantify and are extremely common in most terrestrial environments (Rico-Gray \& Oliveira 2007). Perhaps the most well-documented association between ants and plants in the tropics are those with extrafloral nectaries (EFN-bearing plants) (Rico-Gray \& Oliveira 2007). In these associations, common in more than 100 plant families, the nectar is a liquid rich in carbohydrates (Rico-Gray \& Oliveira 2007) which attracts ants. In exchange for this food, ants defend plants against natural enemies (Rico-Gray \& Oliveira 2007). Recent studies focusing on the structure of binary networks involving ants and EFN-bearing plants have shown that these networks are highly nested (Chamberlain et al. 2010, Dáttilo et al. 2013a). However, it is not known how the frequency of these associations may structure the ecological networks involving these organisms. 
Here we postulate that due to differences in the availability and quality of nectar, the strength of the interaction between ants and plants may change due to the physiological requirements of ants, including their foraging ability. We hypothesized that if there are nectar-composition preferences and competition for best resources among ant species (Blüthgen \& Fiedler 2004), species with high interaction frequency do not necessarily have more links (binary links), or the interaction distribution among partners may not be equitable (different interaction patterns). So, the species' position in the nestedness ranking may be different when compared with binary matrices, in which links of specialists are not necessarily subsets of links of generalists. Specifically, we addressed the following question: Does the nested pattern in ant-plant networks differ between binary or quantitative data? To try to answer this question, we performed nestedness analysis in ant-plant networks from different ecosystems around the world and compared two different nestedness metrics (qualitative and quantitative).

We used quantitative ant-plant networks from the literature along with our extensive database from different tropical ecosystems. The 14 networks used belong to six distinct ecosystems (Table 1). Our ant-plant networks were collected in Amazon tropical rainforest (plot: $250 \times$ $25 \mathrm{~m})\left(9^{\circ} 48^{\prime} \mathrm{S}, 58^{\circ} 15^{\prime} \mathrm{W}\right.$, Brazil), Neotropical savanna (two transects: $1 \mathrm{~km} \times 5 \mathrm{~m})\left(18^{\circ} 58^{\prime} \mathrm{S}, 48^{\circ} 17^{\prime} \mathrm{W}\right.$, Brazil) and dry tropical lowland coastal vegetation (six transects: $1 \mathrm{~km} \times 5 \mathrm{~m})\left(19^{\circ} 6^{\prime} \mathrm{N}, 96^{\circ} 22^{\prime} \mathrm{W}\right.$, Mexico) (unpubl. data). We recorded all occurrences of ants collecting liquids on EFN of each plant.

Using ANINHADO we calculated the NODF metric to estimate nestedness value for binary networks (AlmeidaNeto et al. 2008). To assess if the observed nestedness value was higher than expected by random interaction patterns, we tested nestedness using Null Model II (Bascompte et al. 2003). For quantitative networks we used a recent metric for nestedness analysis based on quantitative matrices called WNODF (Weighted Nestedness Metric Based on Overlap and Decreasing Fill), and tested the WNODF significance using the Null Model RC (Almeida-Neto \& Ulrich 2011). Both nestedness metrics vary from zero (no nestedness) to 100 (perfect nestedness). Note that while the NODF metric independently computes the sequence of decreasing marginal totals and the overlap of pairs, the WNODF metric considers the same NODF principles, but weighted by abundance ranking (Almeida-Neto \& Ulrich 2011).

To compare the frequency of occurrence of significantly nested networks in binary and quantitative matrices, we used maximum likelihood $\chi^{2}$ tests (G tests). A Wilcoxon signed rank test was used to evaluate the difference of nestedness value between the two matrices since our results did not have a normal distribution. Finally, in order

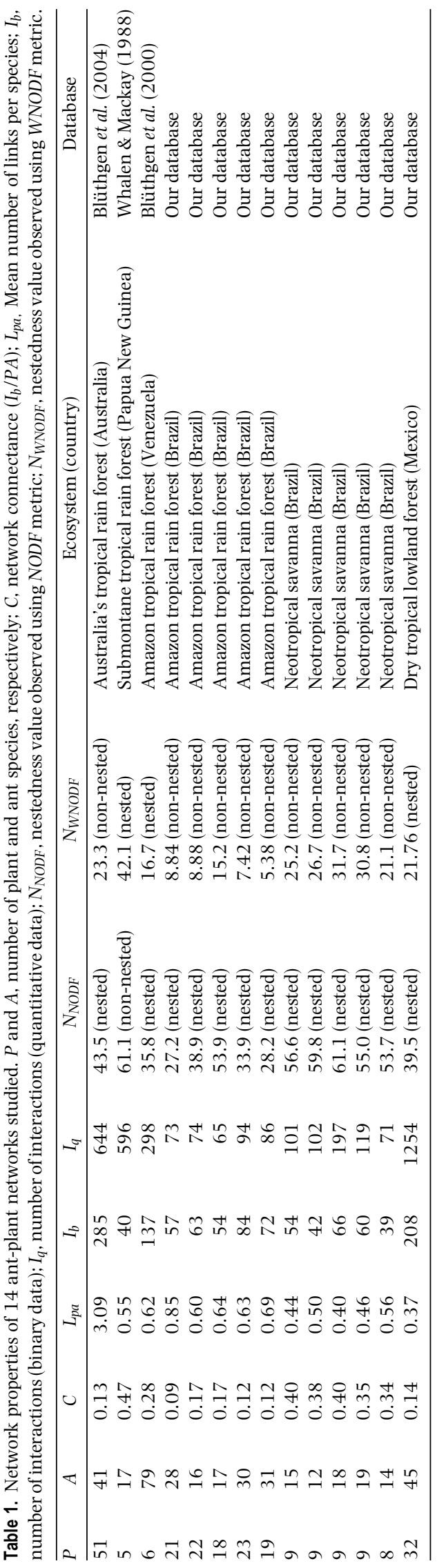


to evaluate whether the number of ant and plant species is proportional to their interaction frequency, we compared the number of links and the frequency of interactions divided by the number of links, using a Spearman rank correlation. This approach was used because the number of links and frequency of species interactions were not independent and could be affected by sampling effects, in which more links imply higher frequency of interactions when more plants are sampled.

The ant-plant networks studied (Table 1) exhibited different nested patterns when analysed using binary or quantitative matrices $(g=14.6, \mathrm{df}=1, \mathrm{P}<0.001)$. Binary networks were often significantly nested (93\% of the networks) whereas most quantitative networks were non-nested (only $21 \%$ of the networks were nested). Only two networks $(14 \%)$ were significantly nested in both binary and qualitative matrices (Amazon,Venezuela, and dry lowland, Mexico). Moreover, binary matrices were more nested $\left(N O D F_{\text {obs }}: 46.3 \pm 12.3\right.$, mean \pm SD) than quantitative matrices $\left(W N O D F_{o b s}: 20.4 \pm\right.$ 10.7) (Wilcoxon signed rank test: $z=3.29, \mathrm{P}<$ 0.001) (Table 1). Also, we observed that in all ant-plant networks the number of links was positively correlated with frequency of species interactions (Spearman rank correlation: Ants: $r_{s}=0.52 \pm 0.11$; Plants: $r_{s}=0.49 \pm$ 0.09 , all $\mathrm{P}<0.05$ ).

As hypothesized, the nested pattern found in ant-plant networks was different when analysed using binary or quantitative data. Unlike binary networks, quantitative networks were often significantly non-nested. These findings suggest that the ecological interpretation of such ant-plant networks can be remarkably different when we evaluate the type of network (qualitative or quantitative). For binary ant-plant networks, we know that relative species abundance is one of the best predictors to explain the origin of the nested pattern (Chamberlain et al. 2010). Such is the case because species tend to find individuals of other abundant species more often than individuals of rare species (Krishna et al. 2008). If ant-plant interactions depend only on ant abundance, it implies no actual competition for the resource, mainly because the individual differences of ants and plants are not taken into account, and therefore all species are ecologically equivalent. However, different biological parameters can change the patterns in which ants and EFN-bearing plants interact in a natural environment and affect the frequency of ants' presence on such plants. For instance, competition, abundance and quality of resources, seasonality of nectar production, nutritional status and dispersal ability of the colony, and other biotic and abiotic factors (Blüthgen \& Fiedler 2004, Dáttilo et al. 2013a).

Most ant species are central place foragers, making foraging trips to food resources but consistently returning to their colony (Yamamoto \& Del-Claro 2008); as a consequence, competition has been identified as an important factor in the structure of ant communities (Blüthgen \& Fiedler 2004). In ant-plant interactions, some ant species can monopolize a particular EFNplant over a long period of time and exhibit a massive recruitment of workers (Blüthgen \& Fiedler 2004). Moreover, due to differences in physiological and ontogenetic conditions of each ant species, one plant species can be a good resource (better quality and amount of nectar) for an ant species and a 'bad' resource for another. Species with lower interaction frequency are not necessarily subsets of species with higher frequency, which generates the non-nested pattern in quantitative networks. Such 'deviating' species are called idiosyncratic species because they show different patterns of interactions from a perfectly nested pattern (AlmeidaNeto \& Ulrich 2011). Therefore, we show that antplant networks are a much more complex system than previously known in the literature based only on binary data.

Several authors have studied the coevolutionary dynamics in ecological networks (Guimarães et al. 2011). The focus of these studies was mainly in the core of highly generalist species, where the interaction strength among interacting partners is symmetrical, with the potential to drive the coevolution of the whole network (Guimarães et al. 2011). We suggest that nestedness analyses using quantitative data could increase the strength of coevolutionary processes involving antplant networks, since the interdependence among species based on interaction frequency is taken into account. However, we did not find the robust core of generalist species in quantitative networks, probably due to the random organization of this community. Furthermore, we observed that species with higher interaction frequency exhibited a higher number of links and that some specific ant-plant interactions were more frequent. We hypothesized that this result is not simply a sampling effect, mainly because these highly interactive species are ant species that have behavioural and ecophysiological adaptations to use liquid food and are possibly competitively superior ant species (massive recruitment and/or aggressive behaviour) (Dáttilo et al. 2013b). Therefore, if such interactions are positive and stable over space and evolutionary time, we should find convergence and complementarity of traits on both sides of the ant-plant interaction (Dáttilo et al. 2013a).

In conclusion, we show that the interaction frequency between ants and plants is an important characteristic to biologically describe the complex networks among these organisms in the tropics. Our results contribute to our understanding of network topology of free-living species. However, it still remains uncertain how these quantitative ecological networks are stable over space and time. In summary, our results show a new perspective of biological 
processes for the study of ecological networks taking into consideration the interaction frequency.

\section{ACKNOWLEDGEMENTS}

We are grateful to Mário Almeida-Neto, Thiago Izzo, and two anonymous reviewers for valuable comments on earlier versions of the manuscript. We also thank the ONFBrasil and the PPBio for logistical and financial support. WD is grateful for financial support by the CNPq and CONACYT. K.D.C. and D.L. thank CNPq for a research grant. This is publication 38 in the NEBAM technical series.

\section{LITERATURE CITED}

ALMEIDA-NETO, M. \& ULRICH, W. 2011. A straightforward computational approach for measuring nestedness using quantitative matrices. Environmental Modelling \& Software 26:173-178.

ALMEIDA-NETO, M., GUIMARÃES, P. R., GUIMARÃES, P., LOYOLA, R. D. \& URLICH, W. 2008. A consistent metric for nestedness analysis in ecological systems: reconciling concept and measurement. Oikos 117:1227-1239.

BASCOMPTE, J., JORDANO, P., MELIÁN, C. J. \& OLESEN, J. M. 2003. The nested assembly of plant-animal mutualistic networks. Proceedings of the National Academy of Sciences USA 100:9383-9387.

BLÜTHGEN, N. 2010. Why network analysis is often disconnected from community ecology: a critique and an ecologist's guide. Basic and Applied Ecology 11:185-195.

BLÜTHGEN, N. \& FIEDLER, K. 2004. Competition for composition: lessons from nectar-feeding ant communities. Ecology 85:14791485 .
BLÜTHGEN, N., VERHAAGH, M., GOITÍA, W., JAFFÉ, K., MORAWETZ, W.\&BARTHLOTT, W. 2000. How plants shape the ant community in the Amazonian rainforest canopy: the key role of extrafloral nectaries and homopteran honeydew. Oecologia 125:229-240.

BLÜTHGEN, N., STORK, N. E. \& FIEDLER, K. 2004. Bottom-up control and co-occurrence in complex communities: honeydew and nectar determine a rainforest ant mosaic. Oikos 106:344-358.

CHAMBERLAIN, S. A., KILPATRICK, J. R. \& HOLLAND, J. N. 2010. Do extrafloral nectar resources, species abundances, and body sizes contribute to the structure of ant-plant mutualistic networks? Oecologia 164:741-750.

DÁTTILO, W., GUIMARÃES, P. R. \& IZZO, T. J. 2013a. Spatial structure of ant-plant mutualistic networks. Oikos 122:1643-1648.

DÁTTILO, W., MARQUITTI, F. M. D., GUIMARÃES, P. R. \& IZZO, T. J. 2013b. The structure of ant-plant ecological networks: is abundance enough? Ecology (in press).

GUIMARÃES, P. R., JORDANO, P. \& THOMPSON, J. N. 2011. Evolution and coevolution in mutualistic networks. Ecology Letters 14:877888.

KRISHNA, A., GUIMARÃES, P. R., JORDANO, P. \& BASCOMPTE, J. 2008. A neutral-niche theory of nestedness in mutualistic networks. Oikos 117:1609-1618.

RICO-GRAY, V. \& OLIVEIRA, P. S. 2007. The ecology and evolution of ant-plant interactions. University of Chicago Press, Chicago. 331 pp.

ULRICH, W., ALMEITA-NETO, M. \& GOTELLI, N. J. 2009. A consumer's guide to nestedness analysis. Oikos 118:3-17.

WHALEN, M. A. \& MACKAY, D. A. 1988. Patterns of ant and herbivore activity on five understorey euphorbiaceous saplings in submontane Papua New Guinea. Biotropica 20:294-300.

YAMAMOTO, M. \& DEL-CLARO, K. 2008. Natural history and foraging behavior of the carpenter ant Camponotus sericeiventris Guérin, 1838 (Formicinae, Campotonini) in the Brazilian tropical savanna. Acta Ethologica 11:55-65. 